\title{
Myotonic dystrophy protein kinase (DMPK) prevents ROS-induced cell death by assembling a hexokinase II-Src complex on the mitochondrial surface
}

\author{
B Pantic ${ }^{1,2}$, E Trevisan ${ }^{1,2}$, A Citta ${ }^{2}$, MP Rigobello ${ }^{2}$, O Marin ${ }^{2,3}$, P Bernardi ${ }^{1,2}$, S Salvatori ${ }^{2}$ and A Rasola*,1,2
}

The biological functions of myotonic dystrophy protein kinase (DMPK), a serine/threonine kinase whose gene mutations cause myotonic dystrophy type 1 (DM1), remain poorly understood. Several DMPK isoforms exist, and the long ones (DMPK-A/B/C/D) are associated with the mitochondria, where they exert unknown activities. We have studied the isoform A of DMPK, which we have found to be prevalently associated to the outer mitochondrial membrane. The kinase activity of mitochondrial DMPK protects cells from oxidative stress and from the ensuing opening of the mitochondrial permeability transition pore (PTP), which would otherwise irreversibly commit cells to death. We observe that DMPK (i) increases the mitochondrial localization of hexokinase II (HK II), (ii) forms a multimeric complex with HK II and with the active form of the tyrosine kinase Src, binding its SH3 domain and (iii) it is tyrosine-phosphorylated by Src. Both interaction among these proteins and tyrosine phosphorylation of DMPK are increased under oxidative stress, and Src inhibition selectively enhances death in DMPK-expressing cells after HK II detachment from the mitochondria. Down-modulation of DMPK abolishes the appearance of muscle markers in in vitro myogenesis, which is rescued by oxidant scavenging. Our data indicate that, together with HK II and Src, mitochondrial DMPK is part of a multimolecular complex endowed with antioxidant and pro-survival properties that could be relevant during the function and differentiation of muscle fibers.

Cell Death and Disease (2013) 4, e858; doi:10.1038/cddis.2013.385; published online 17 October 2013

Subject Category: Experimental Medicine

Nucleotide triplet expansions in the gene encoding for myotonic dystrophy protein kinase (DMPK) cause the most frequent form of muscular dystrophy during adulthood, myotonic dystrophy type $1(\mathrm{DM} 1) .{ }^{1}$ Expanded $(\mathrm{CTG})_{\mathrm{n}}$ repeats in the $3^{\prime}$-untranslated region (UTR) of the DMPK gene are responsible for the complex and multisystemic phenotypic traits of DM1, as aberrant DMPK transcripts accumulate in the nucleus and act in trans on the splicing and expression levels of numerous other genes. ${ }^{2,3}$ In addition, DM1 is characterized by DMPK haploinsufficiency, ${ }^{4-6}$ whose pathological relevance is highlighted by the finding that deletion of the DMPK gene in mice causes late onset myopathy and cardiac abnormalities strikingly similar to those of DM1 patients, ${ }^{7,8}$ where they constitute main causes of lethality. ${ }^{9}$ However, the comprehension of the role played by DMPK in DM1 is hampered by the absence of an extensive characterization of its intracellular functions.

The discovery of a small set of targets of DMPK enzymatic activity suggested its involvement in diverse biological processes, including: (i) splicing regulation, as DMPK phosphorylates the RNA CUG-binding protein
CUG-BP/hNab50; (ii) modulation of $\mathrm{Cl}^{-}$currents and of intracellular $\mathrm{Ca}^{2+}$ homeostasis, after the identification of phospholemman and phospholamban as DMPK substrates; and (iii) cytoskeletal rearrangements and protein quality control, as DMPK interacts with myosin phosphatase-target subunit 1 and with chaperones such as MKBP/HSPB2 (reviewed in Kaliman et $a /^{10}$ ), $\alpha \mathrm{B}$-crystallin/HSPB5 and HSP25/HSPB1. ${ }^{11}$ Nevertheless, DMPK involvement in specific biochemical pathways remains poorly understood. Four out of the seven human DMPK isoforms, that is, the high-molecular weight DMPK-A/B/C/D, are anchored on the cytosolic side of the outer mitochondrial membrane (OMM) with their hydrophobic C-terminal tail; ${ }^{12,13}$ and clues of DMPK-related mitochondrial dysfunction have been reported. Indeed, muscle fibers from $D M P K^{-/-}$mice display swollen mitochondria with an abnormal ultrastructural organization. ${ }^{8}$ Biological processes in which mitochondria have a pivotal role, such as regulation of $\mathrm{Ca}^{2+}$ homeostasis and apoptosis, are altered by changes in DMPK expression. DMPK ${ }^{-/-}$ cardiomyocytes display increased levels of intracellular $\mathrm{Ca}^{2+},{ }^{14}$ whereas the apoptotic process is affected when the

\footnotetext{
${ }^{1}$ CNR Institute of Neuroscience, University of Padova, Padova 35121, Italy; ${ }^{2}$ Department of Biomedical Sciences, University of Padova, Padova 35121 , Italy and ${ }^{3} \mathrm{CRIBI}$ Biotechnology Centre, University of Padova, Padova 35121, Italy

${ }^{*}$ Corresponding author: A Rasola, Dipartimento di Scienze Biomediche, Università di Padova, Viale Giuseppe Colombo 3, Padova I-35121, Italy. Tel: +39 049827 6062; Fax: +39 049827 6361; E-mail: rasola@ bio.unipd.it

Keywords: DMPK; mitochondria; ROS; cell death; hexokinase; Src

Abbreviations: CsA, cyclosporin A; CsH, cyclosporin H; CyP-D, cyclophilin D; DM1, myotonic dystrophy type 1; DMPK, myotonic dystrophy protein kinase; HK II, hexokinase isoform II; MnSOD, manganese superoxide dismutase; NAC, N-acetyl cysteine; OCR, oxygen consumption rate; OMM, outer mitochondrial membrane; PTP, permeability transition pore; RD, rhabdomyosarcoma; ROS, reactive oxygen species; 5-TG, 5-thio-glucose; TMRM, tetramethylrhodamine methyl ester; UTR, untranslated region; VDAC, voltage-dependent anion channel

Received 20.5.13; revised 30.8.13; accepted 04.9.13; Edited by A Finazzi-Agrò
} 
levels of DMPK expression are modulated. ${ }^{15,16}$ Increased levels of reactive oxygen species (ROS) and apoptotic cell death have been reported in myotubes differentiated from DM1 primary myoblasts $^{17}$ and DM1 muscle biopsies, ${ }^{18}$ whereas myoblasts expressing (CTG) $)_{160}$ repeats are more susceptible to apoptosis induced by oxidative stress. ${ }^{19}$ Moreover, an antioxidative and anti-apoptotic role of the DMPK-interacting chaperone MKBP/ HSPB2 was postulated, ${ }^{20,21}$ and oxidative insults could contribute to the stress-induced premature senescence that is observed in DM1 satellite cells. ${ }^{22}$ Notably, muscles are subjected to repeated excitation-contraction cycles, which are characterized by continual series of redox changes; ${ }^{23,24}$ and an altered redox homeostasis could be involved in human muscle chronic diseases, including dystrophies. ${ }^{25}$ Indeed, redox changes must be strictly controlled in order to avoid oxidative damage: a rise in oxidants can prompt opening of the permeability transition pore (PTP) in the inner mitochondrial membrane, irreversibly committing cells to death. ${ }^{26}$ Proteinaceous regulators of the PTP include the chaperone cyclophilin D (CyP-D) in the mitochondrial matrix and the isoform II of hexokinase (HK II) on the OMM. ${ }^{27,28}$ Mitochondrial HK II was found to decrease ROS levels and to inhibit PTP opening induced by oxidative stress. ${ }^{29,30} \mathrm{HK}$ II binding to mitochondria is regulated by kinase signaling pathways, ${ }^{31,32}$ and physiological ROS contribute to the tuning of signal transduction cascades. ${ }^{33}$ Among these, tyrosine kinases of the Src family require ROS for a full enzymatic activity; ${ }^{34}$ in turn, Src can regulate ROS production in localized subcellular districts, ${ }^{35}$ including mitochondria, where Src kinases can locate $^{36}$ to modulate the activity of several targets. ${ }^{37}$

We show here that mitochondrial DMPK, HK II and Src form a multimeric complex on the OMM that protects cells from oxidative stress. The antioxidant and pro-survival properties of such a complex could have a relevant defensive role in a variety of stressful conditions, including redox changes occurring in the course of muscle fiber differentiation and function.

\section{Results}

The human isoform A of DMPK displays a wide tissue distribution and is endowed with a C-terminal tail that can target it to organelles. ${ }^{12}$ In order to study its intracellular distribution and biological activity, we chose human osteosarcoma SAOS-2 cells as a model of recipient cells that do not show detectable levels of endogenous DMPK. Cells were stably transfected either with the wild-type protein or with a kinase-dead (KD) mutant (Figure 1a; transfected cells were dubbed SAOS-2-DMPK and SAOS-2-DMPK KD, respectively), and we found most DMPK in the mitochondrial fraction (Figure 1b). A densitometric analysis performed on equal amounts of mitochondria and cytosol and normalized for the total protein content of each fraction showed that at least $85 \%$ of expressed DMPK is mitochondrial (data not shown). In accord with data from others, ${ }^{12}$ DMPK was associated to the OMM, as it was fully digested by trypsin under conditions that only disrupt external mitochondrial markers (the outer membrane proteins $\mathrm{Bcl}-\mathrm{X}_{\mathrm{L}}$ and TOM-20) without affecting either intermembrane space (AIF and Omi) or matrix (CyP-D) components (Figure 1c). SAOS-2-DMPK cells were characterized by a lower level of mitochondrial superoxide with respect to their mock counterparts (Figure 1d), without any detectable change in the mitochondrial membrane potential or mass, in intracellular ATP levels or in oxygen consumption rate (OCR; Supplementary Figure S1). In most cell types, mitochondria are the main producers of ROS, which are involved in a variety of biological processes, including induction of cell death when their level rises above a critical threshold. ${ }^{38}$ To evaluate whether DMPK could have an impact on cell viability by modulating the mitochondrial redox equilibrium, we placed cells in a medium containing pyruvate and glutamine, but devoid of serum and glucose. Under these conditions, ROS levels are boosted, as cells are forced to utilize the mitochondrial metabolism (see the massive inhibitory effect of the ATP synthase blocker oligomycin on the ATP levels of depleted cells; Supplementary Figure S1d), thus enhancing ROS production by respiratory chain complexes; at the same time cells cannot use glucose to maintain the redox equilibrium through the pentose phosphate pathway (see the DMPK-related differences in the content of oxidized glutathione without changes in the activity of glutathione recycling enzymes, total glutathione and manganese superoxide dismutase (MnSOD) levels; Supplementary Figure S2). Indeed, serum and glucose depletion caused a massive increase of mitochondrial superoxide levels in SAOS-2-mock cells (Figure 1d), which underwent extensive death (Figures 1e and f) caused by oxidative stress, as the antioxidant $\mathrm{N}$-acetyl cysteine (NAC) inhibited both the rise of superoxide levels and cell death (Figures 1d-f). Remarkably, DMPK expression rescued cells from both superoxide increase and oxidative damage, but these protective effects were totally lost in SAOS-2 cells expressing a KD DMPK mutant (Figures 1d-f). DMPK expression also inhibited the surge of mitochondrial ROS and the ensuing mitochondrial depolarization when SAOS-2 cells were exposed to the thiol-oxidant agent diamide (Supplementary Figure S3). Taken together, these results indicate that DMPK exerts an antioxidant role which requires its enzymatic activity.

An increase in mitochondrial superoxide levels can lead to cell death through opening of the mitochondrial PTP, ${ }^{26}$ which is inhibited by cyclosporin A (CsA) through binding of the PTP regulator CyP-D. ${ }^{27}$ We observed that CsA inhibited cell death induced by serum and glucose starvation, whereas both its inactive analogue cyclosporin $\mathrm{H}(\mathrm{CsH})$, and FK506, which inhibits calcineurin, that is a cytosolic target of CsA, were ineffective (Figure 2a). It was recently demonstrated that the mitochondrial localization of HK II suppresses ROS production by these organelles, ${ }^{30,39}$ whereas HK II detachment from the OMM leads to a rapid PTP opening and cell death. ${ }^{40}$ We observed that a higher level of HK II does associate with mitochondria in DMPK-expressing cells, both in complete medium and after serum and glucose withdrawal (Figure 2b). The HK inhibitor 5-thio-glucose (5-TG) abrogated both ROS increase (Figure 2c) and cell death prompted by serum and glucose depletion in SAOS-2-mock cells (Figure 2d), whereas in these conditions 5-TG kept HK II bound to mitochondria (Figure 2e). In addition, a cell permeable synthetic peptide (TAT-HK II), that specifically displaces HK II from OMM, ${ }^{40}$ markedly increased mitochondrial superoxide levels in SAOS2 cells and completely abolished the differences between mock and DMPK-expressing cells (Figure 2f). These results demonstrate that a ROS-induced opening of the PTP is the mechanism that leads to SAOS-2 cell death after serum and 
a

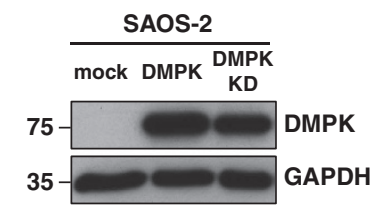

b SAOS-2-DMPK

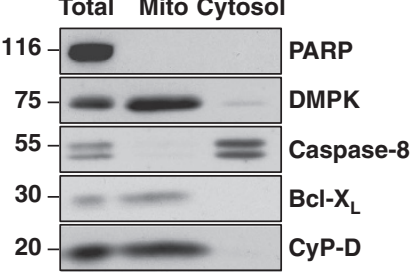

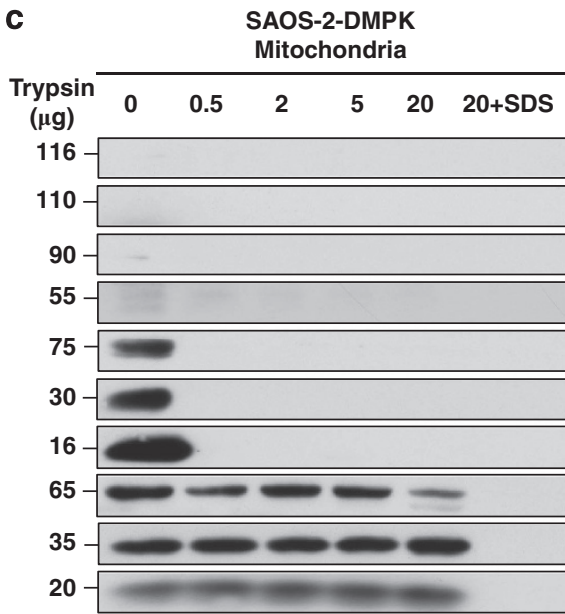

SAOS-2-mock Total Lysates

mock DMPK

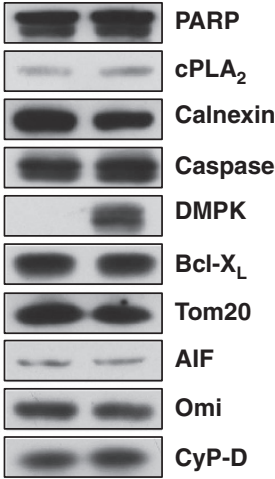

d

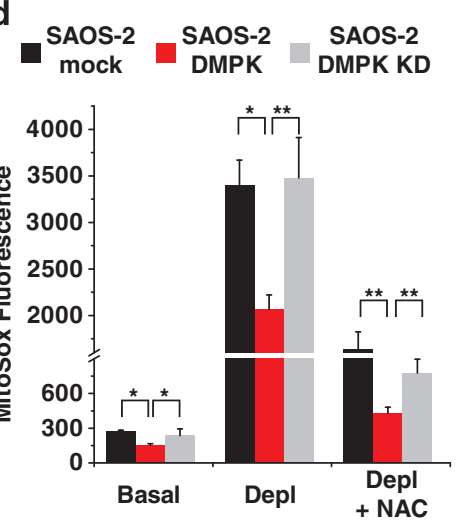

e

$$
\text { e }
$$

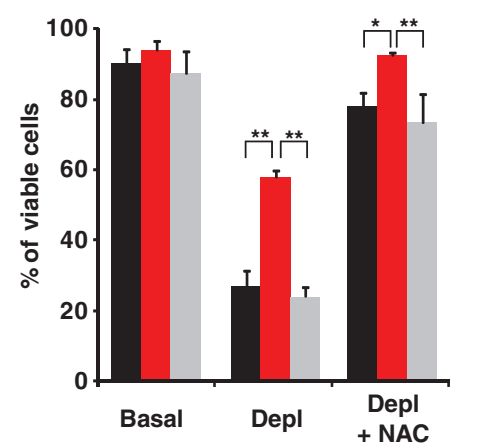

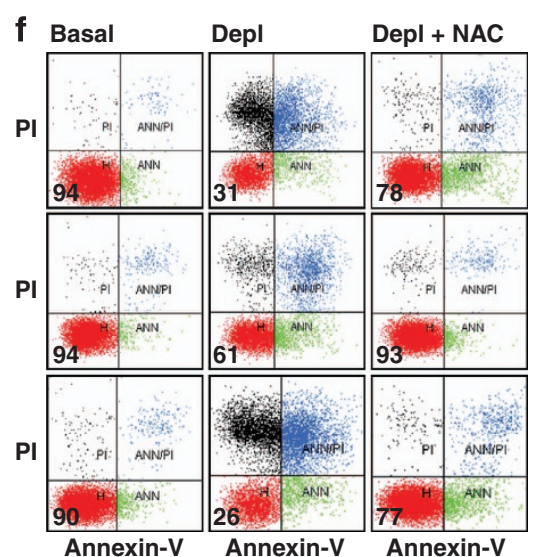

SAOS-2 mock

SAOS-2 DMPK

SAOS-2 DMPK KD

Figure 1 Human DMPK isoform A (hDMPK-A) associates with the mitochondria and its kinase activity prevents ROS-induced cell death. (a) hDMPK-A expression on human osteosarcoma SAOS-2 cells stably transfected with plasmids carrying either a mock construct or a wild-type hDMPK-A or a KD hDMPK-A mutant. GAPDH was used as a loading control of the western immunoblot. (b) Subcellular fractionation and western immunoblot of the mitochondrial and cytosolic fractions of SAOS-2-DMPK cells. PARP and caspase- 8 were used as the nuclear and cytosolic markers, respectively; Bcl- $X_{L}$ and CyP-D were used as mitochondrial markers. Thirty micrograms of cytosolic or mitochondrial proteins were loaded per lane. (c) Partial trypsin digestion of mitochondria isolated from SAOS-2-DMPK cells. PARP, caspase-8 and cPLA2 were used as cytosolic markers; calnexin as endoplasmic reticulum marker; $\mathrm{BCl}-\mathrm{X}_{\mathrm{L}}$ and Tom-20 as OMM markers; AIF and Omi as mitochondrial intermembrane space markers and CyP-D as a marker of mitochondrial matrix. Fifty micrograms of mitochondrial or total cell lysates were loaded per lane. (d) Cytofluorimetric analysis of mitochondrial superoxide levels in complete medium (Basal) or after $24 \mathrm{~h}$ of serum and glucose depletion (Depl) of SAOS-2 cells in the absence and presence of $\mathrm{N}$-acetyl cysteine (NAC, $1 \mathrm{mM}$ ). Bars show the mean fluorescence intensity \pm S.D. of the Mitosox probe for $10^{4}$ recorded cells $\left(n=3,{ }^{*} P<0.05\right.$; $\left.{ }^{* *} P<0.01\right)$. (e) Cytofluorimetric analysis of cell death in complete medium (Basal) or after $24 \mathrm{~h}$ of serum and glucose depletion (Depl). Bars represent mean percentages \pm S.D. of viable, Annexin-V and propidium iodide negative, cells $\left(n=3,{ }^{*} P<0.05\right.$; $\left.{ }^{* *} P<0.01\right)$. (f) Representative traces of cytofluorimetric cell death analysis by Annexin-V and propidium iodide staining. In red, double negative, viable cells; in green, Annexin-V positive, apoptotic cells; in blue, Annexin-V/PI double positive, late apoptotic cells; in black, PI positive, necrotic cells. Numbers indicate the percentages of viable cells

glucose starvation, and that DMPK protects cells by increasing HK II binding to mitochondria, thus keeping low the mitochondrial ROS levels.

In accord with this model, DMPK co-immunoprecipitated with HK II both in basal conditions and after starvation, and this interaction did not alter the well-known association of HK II with VDAC1 (Figure 3a). Given that the mitochondrial localization of $\mathrm{HK}$ II is regulated by kinase signaling, ${ }^{31,32}$ we explored the possibility that also the interaction between $\mathrm{HK}$ II and DMPK could be modulated by phosphorylation events. An in silico analysis revealed a proline-rich region in the DMPK sequence, the amino-acid stretch in position 350-356, on the exposed surface in the AGC-kinase $\mathrm{C}$-terminal region, which constitutes a non-canonical class I recognition-binding site for the SH3 domain of the Src tyrosine kinase family (ELM-the database of eukaryotic linear motifs (PMID:22110040)).
Prompted by this observation, we investigated whether Src interacts with HK II/DMPK and found that (i) Src co-immunoprecipitates with HK II, (ii) the presence of DMPK strongly enhances the HK II/Src interaction and (iii) a fraction of Src associated with HK II and DMPK is in its active form (Figure 3a). Conversely, both HK II and DMPK co-immunoprecipitated with Src (Figure $3 b$ ), and this interaction was markedly increased after serum and glucose depletion (Figure 3b), when the tyrosine kinase activity of Src was also enhanced (Figure 3a). In accord with the in silico analysis, we also found an interaction between DMPK and the SH3 domain of Src (Figure 3c), and Src partially localized in the mitochondria (Figure 3d). Moreover, treatment with a specific dual site Src inhibitor, Srcl-1, followed by a low concentration of TAT-HK II peptide (that did not affect cell survival per se) selectively induced cell death in 


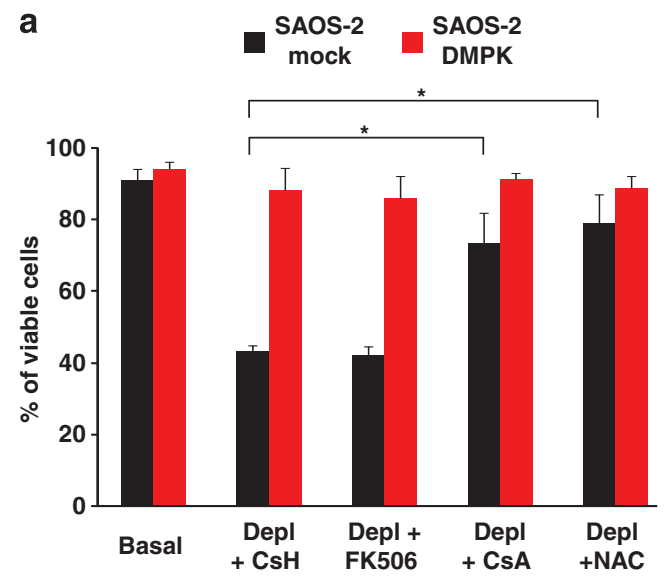

b

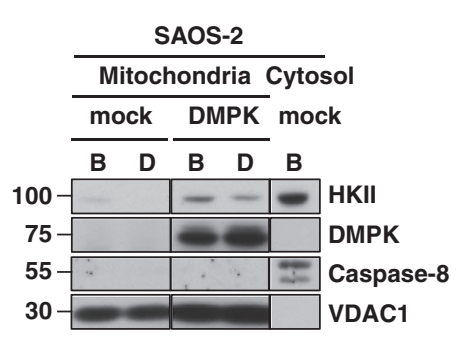

e $\frac{\text { SAOS-2-mock }}{\text { Cytosol }} \frac{\text { Mito }}{-\mathrm{TG}++}$
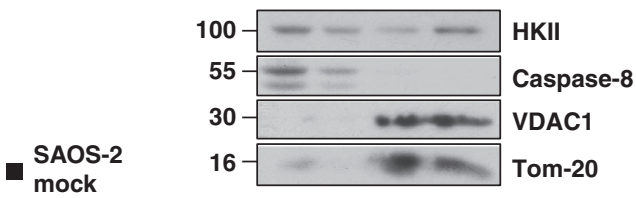

SAOS-2

SAOS-2
DMPK

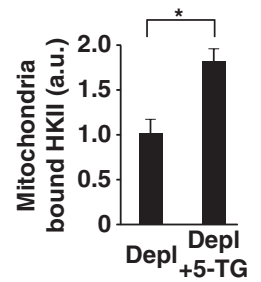

c
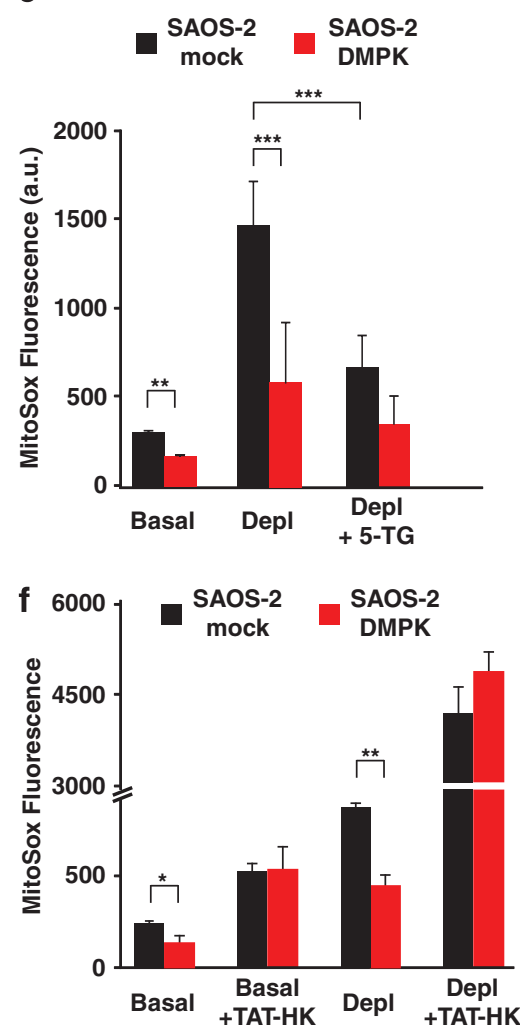

Figure 2 DMPK protects from mitochondrial ROS and cell death by favoring HK II association with the mitochondria. (a) Cytofluorimetric analysis of cell death was performed as in Figure 1e on SAOS-2 cells kept in complete medium (Basal) or after $16 \mathrm{~h}$ of serum and glucose depletion (Depl) in the presence of the PTP inhibitor CsA $(1.6 \mu \mathrm{M})$ or its negative controls $\mathrm{CsH}$ and FK506 (1.6 $\mu \mathrm{M}$ each) or NAC (1 mM). Bars represent mean percentages \pm S.D. ( $n=3$, * $P<0.05)$. (b) Western immunoblot of mitochondrial and cytosolic fractions of SAOS-2 cells grown either in basal condition (B, complete medium) or without serum and glucose for $8 \mathrm{~h}$ (D, depletion). Thirty micrograms of mitochondrial and cytosolic proteins were loaded per lane. Caspase-8 and VDAC1 were used as cytosolic and mitochondrial markers, respectively. (c) Cytofluorimetric analysis of mitochondrial superoxide levels in SAOS-2 cells kept in complete medium (Basal) or without serum and glucose for $16 \mathrm{~h}$ (Depl, depletion). Where indicated, the HK II inhibitor 5-TG $(10 \mathrm{mM})$ was added. Bars represent mean fluorescence values \pm S.D. $\left(n=4,{ }^{* \star} P<0.01\right.$; $\left.{ }^{* *} P<0.001\right)$ (d) Cytofluorimetric analysis of cell death was performed as in Figure 1e on SAOS-2 cells kept in complete medium (Basal) or after $16 \mathrm{~h}$ of serum and glucose depletion (Depl) in the presence of either CsH $(1.6 \mu \mathrm{M})$ or 5 -TG $(10 \mathrm{mM})$. Bars represent mean percentages \pm S.D. $\left(n=3,{ }^{* \star} P<0.01\right)$. (e) Western immunoblot of mitochondrial and cytosolic fractions $(50 \mu \mathrm{g}$ each) isolated from SAOS-2 mock cells depleted of serum and glucose (8h) with or without 5-TG (10 mM). Caspase-8 was used as a cytosolic marker, VDAC1 and Tom-20 as mitochondrial markers. The bar graph shows the densitometric quantification of HK II bands in mitochondrial fractions of SAOS-2-mock cells, corrected for the relative amounts of VDAC1, Tom-20 and CyP-D. Obtained values were normalized to Depl condition. (f) Cytofluorimetric analysis of mitochondrial superoxide in complete medium (Basal) or after $8 \mathrm{~h}$ serum and glucose depletion (Depl) in the absence or presence of the HK II displacing peptide (TAT-HK, $20 \mu \mathrm{M}$ ). TAT-HK II peptide was added for the last 45 min before the detachment of the cells. Bars represent mean fluorescence values \pm S.D. $\left(n=4,{ }^{*} P<0.05 ;{ }^{*} P<0.01\right)$

DMPK-expressing cells (Figure $3 e$ ). In an in vitro assay, Src could phosphorylate DMPK on Tyr residues (Figure 4a), and the immunoprecipitation of phospho-Tyr residues indicated that Tyr phosphorylation of DMPK was increased in starved SAOS-2 cells (Figure 4b). To confirm this phosphorylation, we expressed in SAOS-2 cells a FLAGtagged DMPK, whose immunoprecipitation in starvation conditions further showed a Src-dependent Tyr phosphorylation of DMPK (Figure 4c). The KD DMPK mutant is unable to shield cells from oxidative stress (see Figure 1). We found that in in vitro conditions, DMPK can phosphorylate Src on Ser/Thr residues (Figure 4d), which was reported to enhance Src activity. ${ }^{41}$ Taken together, these observations imply that both DMPK and Src are required to increase HK II association with the OMM, and that the assembly of this protective multimeric complex can be modulated by the kinase activity of Src and DMPK.
In a mirror strategy of analysis of DMPK function, we performed stable DMPK RNA interference on human rhabdomyosarcoma (RD) cells, which arise from muscle precursor cells. Silenced cells (termed RD-shDMPK) showed a reduction of more than $90 \%$ of both $75 \mathrm{kDa}$ mitochondriabound and $70 \mathrm{kDa}$ cytosolic DMPK isoforms (Figure $5 \mathrm{a}$ and Figure 6a). As in SAOS-2 cells, DMPK presence maintained the levels of mitochondrial superoxide low in RD-mock cells (Figure 5b), shielding from the lethal effects of the oxidative insults generated by the serum and glucose withdrawal (Figures $5 c$ and $d$ ). Levels of oxidized glutathione were increased in DMPK-short hairpin RNA cells, without significant differences in the levels of total glutathione, mitochondrial MnSOD or in the activity of glutathione reductase and thioredoxin reductase (Supplementary Figure S4). In good match with our observations on the SAOS-2 model, in RD cells (i) the presence of DMPK favored HK II association with the 
a
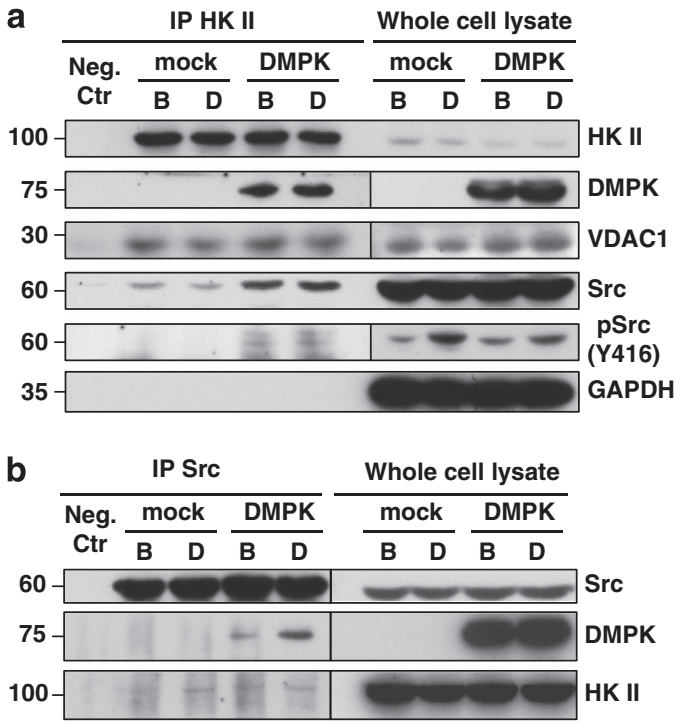
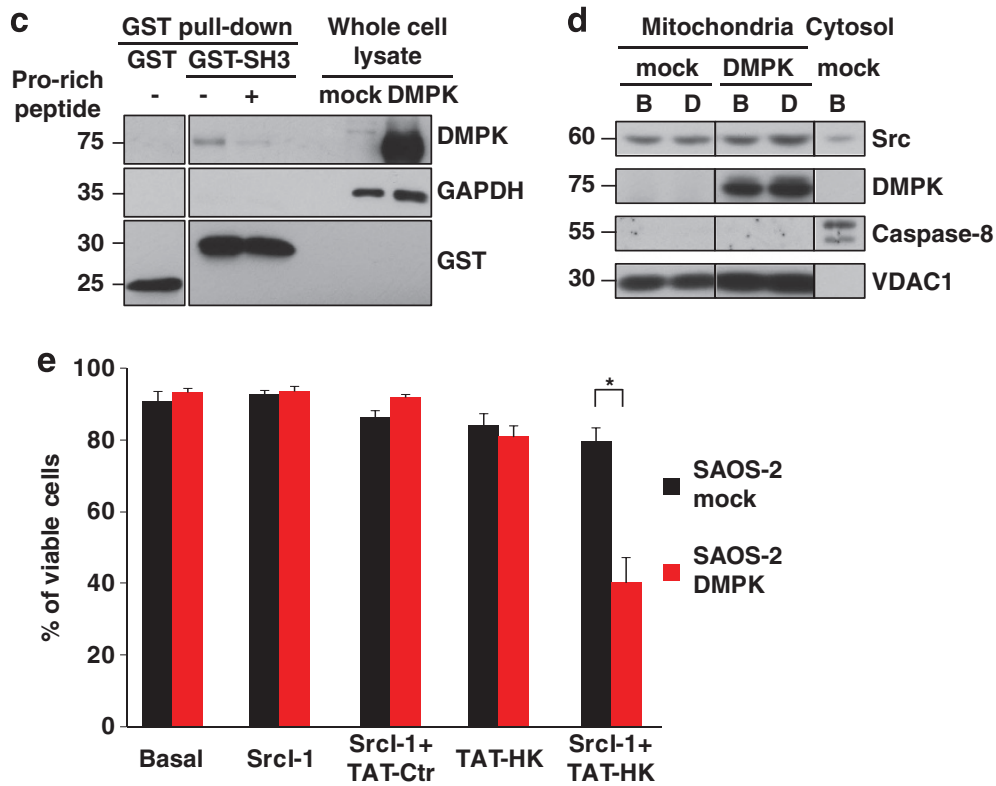

Figure 3 DMPK interacts with HK II and Src in SAOS-2-DMPK cells. (a) Immunoprecipitation (IP) of HK II on lysates obtained from SAOS-2 cells grown in complete medium (B, basal) or after $8 \mathrm{~h}$ of serum and glucose depletion (D). GAPDH was used to exclude the presence of residual supernatant contamination in IP. (b) IP of Src on lysates obtained from SAOS-2 cells grown in complete medium (B) or after $8 \mathrm{~h}$ of serum and glucose depletion (D). (c) Pulldown of the Src GST-SH3 domain on SAOS-2-DMPK cell lysates with or without a SH3 competing proline-rich peptide $(200 \mu \mathrm{M})$. The GST domain was used as a negative control, and GAPDH as a loading control. (d) Mitochondrial and cytosolic proteins $(30 \mu \mathrm{g})$ were isolated from cells grown in complete medium (B) or from cells depleted of serum and glucose for $8 \mathrm{~h}$ (D). Caspase-8 and VDAC1 were used as cytosolic and mitochondrial markers, respectively. (e) Cytofluorimetric analysis of cell death was performed as in Figure 1e on SAOS-2 cells treated either with a control peptide or with a HK II peptide linked to the TAT sequence (TAT-Ctr or TAT-HK II, respectively, $20 \mu \mathrm{M}$ each) for $45 \mathrm{~min}$; where indicated, cells were preincubated with the Src inhibitor Srcl-1 (10 $\mu \mathrm{M}$ ) for 30 min. Bars represent mean percentages \pm S.D. $\left(n=3,{ }^{*} P<0.05 ;{ }^{* *} P<0.01\right)$. In all the IPs of the figure, $50 \mu \mathrm{g}$ of total cell lysate was used as loading control

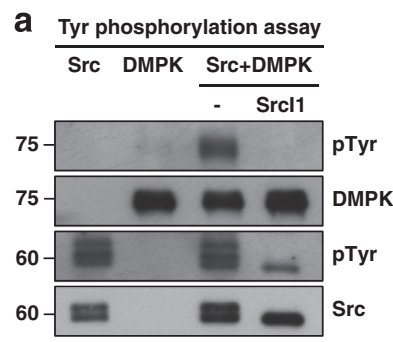

C

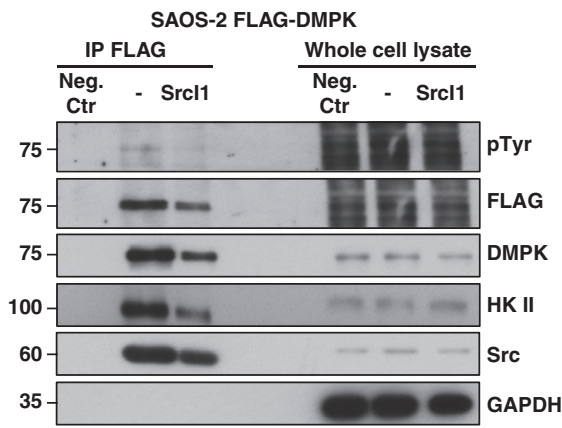

b

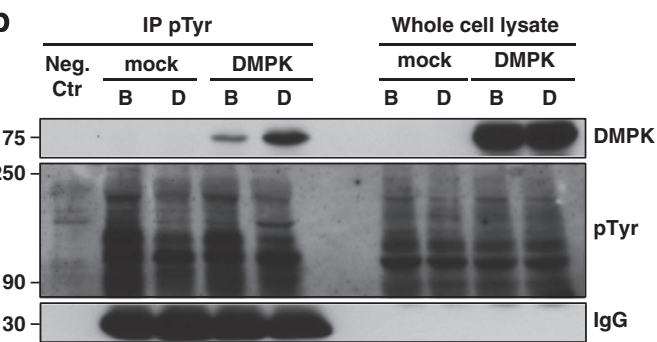

d

Ser/Thr phosphorylation assay

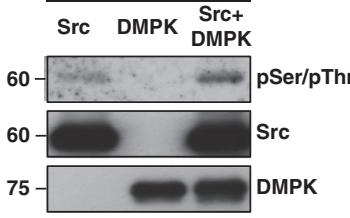

Figure 4 Src and DMPK can phosphorylate each other. (a) Western immunoblot of an in vitro tyrosine phosphorylation assay performed by incubating active recombinant Src (40 ng) with recombinant DMPK (200 ng) with or without the Src inhibitor Srcl-1 $(10 \mu \mathrm{M})$. (b) IP of proteins phosphorylated on tyrosine residue (s) (pTyr) from SAOS-2 cells grown in complete medium (B, basal) or depleted of serum and glucose for $8 \mathrm{~h}$ (D). (c) IP of FLAG-tagged DMPK transiently expressed in wild-type SAOS-2 cells starved as in (b) with or without the Src inhibitor Srcl-1 $(10 \mu \mathrm{M})$. (d) Western immunoblot of an in vitro serine/threonine phosphorylation assay performed by incubating recombinant DMPK $(600 \mathrm{ng})$ with recombinant $\mathrm{Src}(400 \mathrm{ng})$

mitochondria (Figure 6a), (ii) the mitochondrial DMPK isoform(s) interacted with HK II (Figure 6b), (iii) both DMPK and HK II co-immunoprecipitated with Src (Figure 6c) and (iv) Src inhibition followed by treatment with the TAT-HK II peptide markedly depolarized mitochondria of mock, DMPK-expressing cells, whereas it was ineffective on shDMPK cells (Figure 6d). 

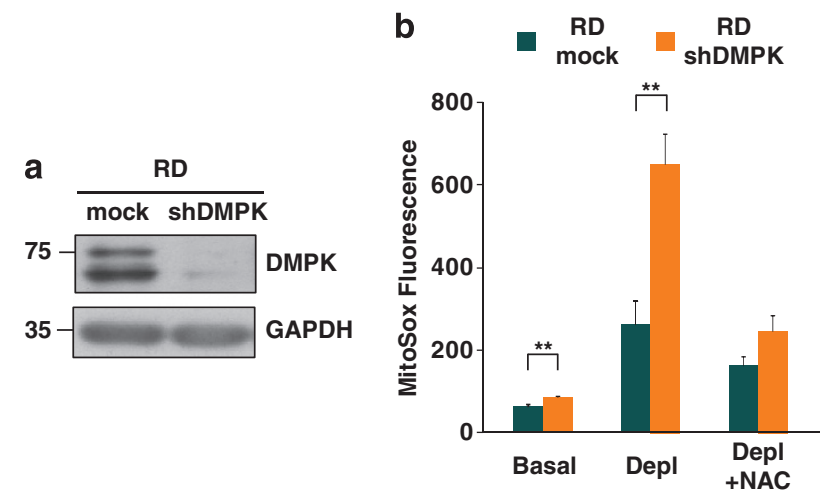

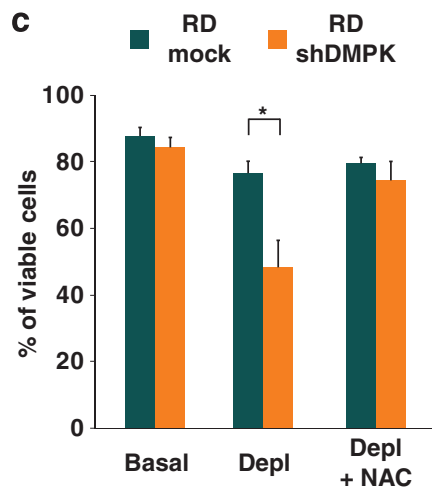

d

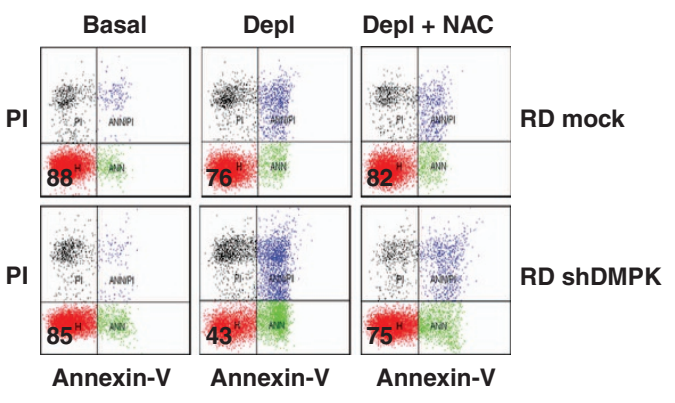

Figure 5 Silencing of endogenous DMPK in RD cells increases mitochondrial superoxide and cell death. (a) Western immunoblot of total cell lysates (50 $\mu \mathrm{g}$ ) of RD-mock and RD-shDMPK cells. Endogenous DMPK is present in RD-mock cells as mitochondrial high MW isoforms ( $75 \mathrm{kDa})$ and cytosolic low MW (70 kDa) isoforms. GAPDH was used as a loading control. (b) Cytofluorimetric analysis of mitochondrial superoxide levels of RD cells grown in complete medium (Basal) or after $24 \mathrm{~h}$ of serum and glucose depletion (Depl). Where indicated, depletion was carried out in the presence of NAC $(2.5 \mathrm{mM})$. Bars represent mean fluorescence values \pm S.D. $\left(n=3\right.$, $\left.{ }^{*} P<0.01\right)$. (c) Cytofluorimetric analysis of cell death was performed as in Figure 1e on RD cells grown in complete medium (Basal) or after $24 \mathrm{~h}$ of serum and glucose depletion (Depl). Bars represent mean percentages \pm S.D. $\left(n=3,{ }^{*} P<0.05\right)$ of viable, Annexin-V and propidium iodide negative, cells. (d) Representative traces of cytofluorimetric cell death analyses by Annexin- $V$ and propidium iodide staining are shown as in Figure 1f. Numbers indicate the percentages of viable cells

RD cells possess muscle-specific transcription factors such as MyoD (Figure 7a) and can undergo in vitro myogenic differentiation leading to myotube formation. This can be elicited by lowering the extracellular concentration of TGF- $\beta$ via phorbol ester stimulation in low serum conditions. ${ }^{42}$ After 7 days of in vitro differentiation, RD-mock cells expressed adult myosin heavy chain (MHC MF20; Figure 7a), a sarcomeric motor protein that is a hallmark of differentiated adult muscle, ${ }^{43}$ and formed multinucleated myotubes (Figure $7 \mathrm{~b}$ ). Conversely, RD-shDMPK cells did not undergo differentiation, yet the ability to express MHC MF20 and to form myotubes was recovered by adding NAC in the differentiation medium (Figures $7 a$ and b). After 7 days of differentiation, mitochondrial superoxide levels were increased and this rise was higher in RD-shDMPK cells as compared with mock cells. NAC prevented the superoxide rise in shDMPK cells (Figure 7c) and inhibited caspase-3 activation (Figure 7a), suggesting that ROS-induced cell death contributed to the lack of myotube formation in RD-shDMPK cells.

\section{Discussion}

In the present study we have identified a novel biological function of DMPK, which requires the formation of a multimeric complex with $\mathrm{HK}$ II and the tyrosine kinase Src on the
OMM. The tight functional interplay among DMPK, HK II and Src protects from oxidative insults, shielding cells from the risk of lethal PTP opening. We also observed a previously undetected Tyr phosphorylation of DMPK, which is enhanced under starvation conditions that expose cells to a robust oxidative stress. Consistently, in these conditions both the interaction between DMPK and Src, and the Src kinase activity markedly increase. Src activation is a master event in the preservation of normal cell homeostasis, and it regulates cytoskeleton organization, maintenance of normal intercellular contacts, and cell adhesion, motility, proliferation and survival. ${ }^{44} \mathrm{~A}$ growing body of evidence indicates that $\mathrm{Src}$ has a pivotal role in the Tyr phosphorylation of mitochondrial proteins, which is emerging as a major regulation pathway of mitochondrial functions such as respiration and ATP synthesis and apoptosis modulation. ${ }^{37,45}$ In order to attain its maximal kinase activity, Src must undergo autophosphorylation at the Tyr416 residue in the activation loop and a further cysteine oxidation on this already open conformation of the enzyme. ${ }^{35}$ Therefore, environmental conditions that prompt an increase in intracellular ROS levels induce full Src activation, which in turn is involved in the regulation of localized ROS production. ${ }^{35}$ Taken together, these observations make Src a specific sensor of intracellular redox state, placing it at the center of feedback regulatory loops that keep 

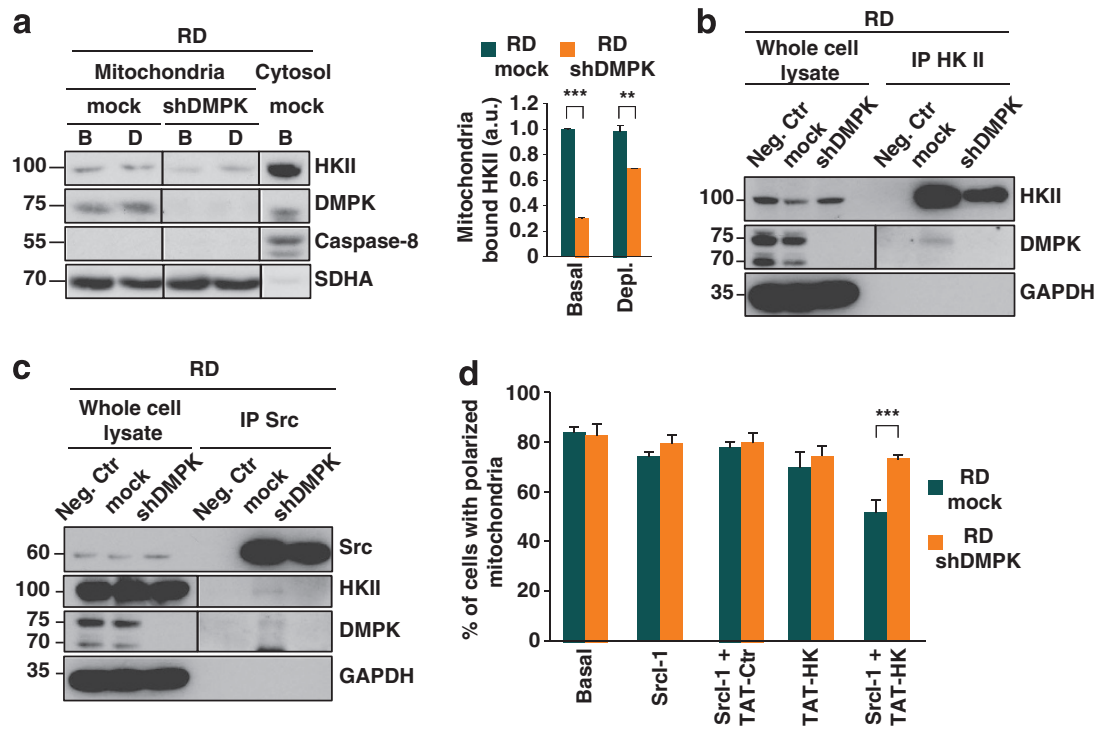

Figure 6 Endogenous mitochondrial DMPK interacts with HK II and Src in RD cells. (a) Western immunoblot of mitochondrial and cytosolic fractions ( $30 \mu \mathrm{g}$ each) obtained from RD-mock and RD-shDMPK cells grown either in complete medium (B, basal conditions) or kept for $24 \mathrm{~h}$ without serum and glucose (D, depletion). Caspase-8 and SDHA were used as cytosolic and mitochondrial markers, respectively. The bar graph reports the densitometric analysis of HK II bands in mitochondrial fractions, corrected for the amount of SDHA and normalized to basal condition of RD-mock cells. (b and c) IP of HK II (b) and of Src (c) on lysates from RD-mock and RD-shDMPK cells. Total cell lysates $(50 \mu \mathrm{g})$ were used as loading controls; GAPDH was used to exclude the presence of residual supernatant contamination in the IP. (d) Cytofluorimetric analysis of mitochondrial depolarization by TMRM staining of RD cells. Cells were treated either with a control peptide or with a HK II peptide linked to the TAT sequence (TAT-Ctr or TAT-HK II, respectively, $20 \mu \mathrm{M}$ each) for $45 \mathrm{~min}$; where indicated, cells were preincubated with the Src inhibitor Srcl-1 $(10 \mu \mathrm{M})$ for 30 min. Bars represent mean percentages \pm S.D. $\left(n=5,{ }^{*} P<0.001\right)$ of cells whose mitochondria maintained a high TMRM staining, that is, their mitochondrial membrane potential
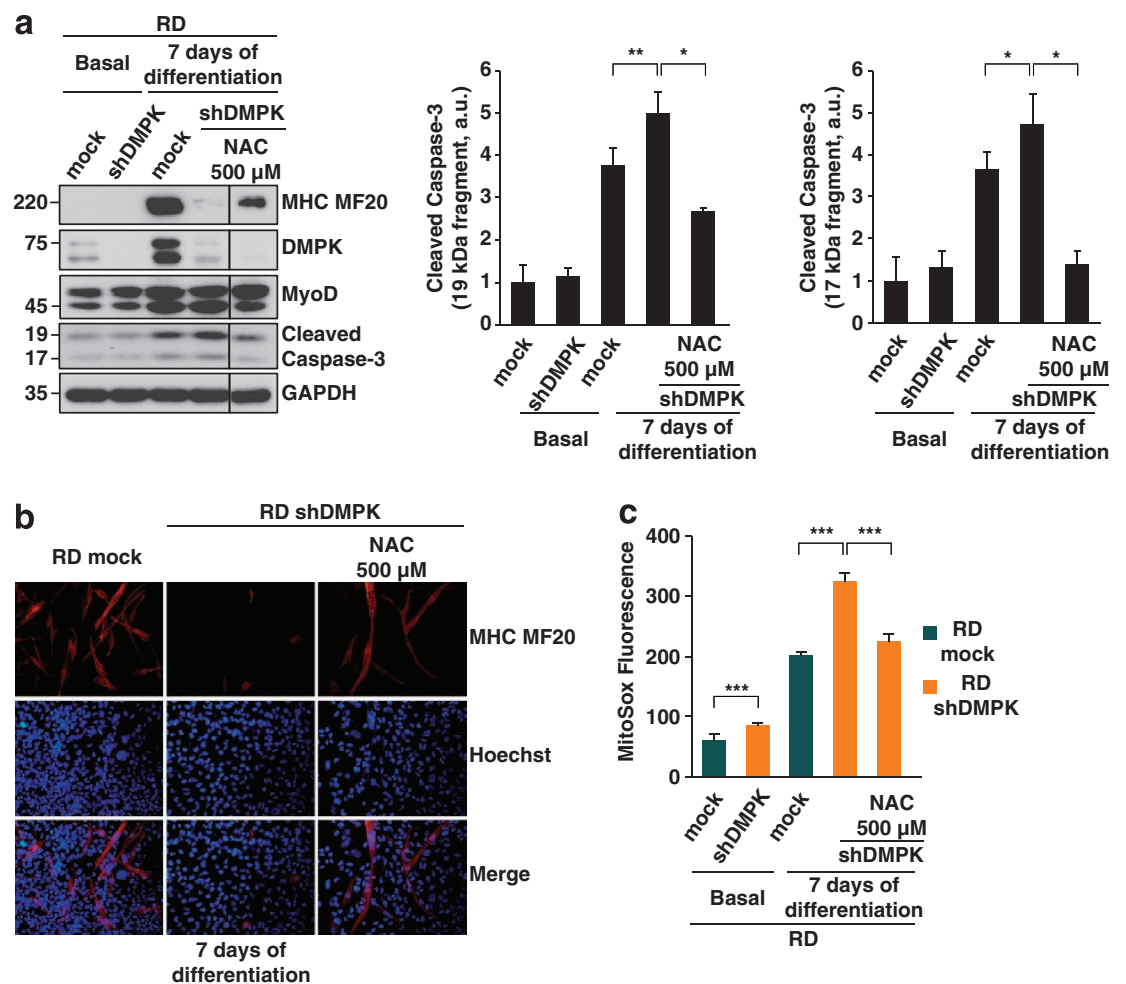

Figure 7 Lack of endogenous DMPK impairs myotube formation of RD cells by increasing oxidative stress. (a) Western immunoblot of RD cells grown in complete medium (basal) or after 7 days of differentiation. Where indicated, differentiation was carried out in the presence of NAC. Adult MHC MF20 was used as a marker of myotube formation; cleaved caspase-3 as an indicator of apoptosis and GAPDH as a loading control. Bar graphs report the densitometric analysis of cleaved caspase-3 fragments (19 and $17 \mathrm{kDa}$ ), corrected for the amount of GAPDH and normalized to basal conditions of RD-mock cells. (b) Immunofluorescence on RD cells after 7 days of differentiation. Adult MHC MF20 and Hoechst were used to stain myotubes and nuclei, respectively. As expected, myotubes are endowed with multiple nuclei; where indicated, differentiation was carried out in the presence of NAC. (c) Cytofluorimetric analysis of mitochondrial superoxide levels in RD cells grown in complete medium or after 7 days of differentiation. Experimental conditions are as in (a); values indicate Mitosox fluorescence \pm S.D. $\left(n=5,{ }^{* *} P<0.01 ;{ }^{* * *} P<0.001\right)$ 
intracellular redox homeostasis. We find that Src protects from ROS-dependent PTP opening caused by HK II detachment from the mitochondria. This protection occurs in a DMPK-sensitive fashion, as the inhibition of Src enzymatic activity selectively affects the viability of DMPK-expressing cells, in accord with a general survival and antioxidant function of mitochondrial Src. Moreover, we have shown that the kinase activity of DMPK is required for its antioxidant function, and that DMPK directly binds the SH3 domain of Src. We also observe that, at least in in vitro conditions, DMPK can phosphorylate Src on Ser/Thr residues, which contributes to Src activation. ${ }^{41}$ Therefore, a feedback loop can be envisaged in which conditions of oxidative stress conditions boost Src activity, leading to an activating Tyr phosphorylation of DMPK. In turn, active DMPK would phosphorylate Src on Ser/Thr residues, thus contributing to the maintenance of its induction. At variance from our observations, a pro-apoptotic role was attributed to the human DMPK-A isoform when transiently expressed in different mouse cell lines, where it locates to the mitochondria. ${ }^{16}$ However, the same apoptosis induction was caused by expressing only the C-terminal tail of DMPK, raising the possibility that the observed noxious effects were directly caused by some peculiar properties of the mitochondria-anchoring tail rather than by the function of the kinase.

We demonstrate that DMPK promotes the mitochondrial binding of $\mathrm{HK} \mathrm{II}$, which directly blocks the increase in mitochondrial superoxide levels elicited by starvation. Indeed, the mitochondrial detachment of HK II by a selective peptide not only amplifies the ROS surge caused by the serum and glucose depletion but it also annihilates differences in ROS levels between cells with or without DMPK. The antioxidant function of HK II relies on its mitochondrial binding per seand it is independent of its enzymatic activity, as (i) it occurs under conditions of glucose depletion, that is, in the absence of the HK II substrate and (ii) it is enhanced by a HK II blocker, 5-TG, which competes for glucose in the active site of the enzyme and increases HK II binding to the mitochondria. Accordingly, it was shown that the mitochondrial localization of catalytically inactive $\mathrm{HK}$ I or II protects against oxidative insults. ${ }^{29}$ Nevertheless, a molecular dissection of the mechanism(s) by which the mitochondrial HK II safeguards cells from potentially lethal insults is still lacking. We and others have demonstrated that the mitochondrial binding of HK II prevents the opening of the PTP and the ensuing cell death, ${ }^{40,46-48}$ and it is largely established that ROS are a powerful PTP inducer. ${ }^{26}$ Thus, the antioxidant function of the mitochondrial HK II could have a key survival role by maintaining the PTP locked, as recently proposed for cardiomyocytes. ${ }^{30}$ It remains unclear how HK II takes part in ROS regulation. It was proposed that mitochondrial HKs could protect from oxidative damage by eliciting $\mathrm{PKC} \varepsilon$-mediated phosphorylation of the voltage-dependent anion channel (VDAC) in the OMM, even if this model does not explain how phosphorylated VDAC could maintain a low redox level. ${ }^{29}$

Here we have shown that the interaction among HK II, DMPK and Src is crucial to keep redox homeostasis under control. In principle, this could be achieved by decreased ROS production, by increased ROS scavenging or both. Although increased scavenging cannot be completely ruled out, all the ROS scavenging systems that we have analyzed did not show any DMPK-related difference. On the other hand we observed an increased pool of oxidized glutathione after glucose starvation in cells without DMPK. In the absence of glucose, cells cannot reduce glutathione, as this reaction requires NADPH generated in the pentose phosphate pathway downstream to glucose phosphorylation. Thus, in cells lacking DMPK, starvation could elicit a stronger oxidative stress, depleting the antioxidant activity of the glutathione system. The main sources of mitochondrial superoxide are respiratory chain complexes, and changes in their activity can crucially contribute to altered redox homeostasis that can lead to PTP opening. ${ }^{49}$ We could not measure any difference in the rate of oxygen consumption between cells with or without DMPK, not even under starvation conditions. However, we cannot exclude that more subtle regulatory events on specific respiratory complexes occur in DMPK-expressing cells. Both skeletal muscle fibers and cardiomyocytes boost mitochondrial respiration, on which they heavily rely for ATP synthesis; thus, even small changes in respiration could account for differences in superoxide levels.

It is tempting to speculate on the possible implications of our findings on DM1 pathogenesis. Both $d m p k^{-/-}$mice ${ }^{50}$ and DM1 patients ${ }^{51}$ show insulin insensitivity, which was related to a switch in the expression of insulin receptor isoforms. As it was proposed that redox dysregulation following a rise in mitochondrial ROS is a major factor in the onset of insulin resistance, ${ }^{52,53}$ this phenotypic trait could be related to DMPK haploinsufficiency in DM1. Moreover, mitochondrial dysfunction could be involved in the selective atrophy of type 1 (slow) fibers that characterizes $\mathrm{DM} 1,{ }^{54,55}$ as these fibers are prevalent in the red, mitochondria-rich muscles. ${ }^{56}$

We have also observed that the antioxidant activity of the DMPK/HK II/Src complex is essential for myotube differentiation of RD cells. Sequential redox changes are coupled to muscle contraction activity ${ }^{23,24}$ and disruption of redox equilibria is observed in diverse muscle diseases. ${ }^{25}$ Nevertheless, little is known on the role played by oxidants in the process of muscle differentiation. Our data argue for the importance of keeping the mitochondrial superoxide levels low during myotube formation, possibly in order to avoid PTP induction and the ensuing commitment to death of the differentiating cells. Given the complex and dynamic regulation of ROS homeostasis, even a partial loss of DMPK function could have important effects on muscle differentiation, with major implications for DM1 pathogenesis.

In conclusion, the existence of a multimolecular complex composed by DMPK, HK II and Src on the mitochondrial surface, and its role in redox regulation could have important pathophysiological implications that extend beyond regulation of myogenesis.

\section{Materials and Methods}

Cell cultures and plasmid constructs. The cDNA of human DMPK isoform A (NM_004409.3, Origene, Rockville, MD, USA) was sub-cloned into the pcDNA3.1 $(+)$ vector (Invitrogen, Carlsbad, CA, USA) and stably expressed in human osteosarcoma SAOS-2 cells selected with $150 \mu \mathrm{g} / \mathrm{ml}$ of zeocin (Invivogen, San Diego, CA, USA). The KD DMPK mutant was obtained by mutating DMPK lysine 100 into alanine with a QuikChange II XL Site-Directed Mutagenesis Kit (Agilent, Santa Clara, CA, USA) and stably expressed in human osteosarcoma SAOS-2 cells selected with $150 \mu \mathrm{g} / \mathrm{ml}$ of zeocin. Mutagenic primers were: 5'-CGGGCCAGGTGTATGCCATGGCAATCATGAACAAGTGGGACAT-3' (forward) 
and $\quad 5^{\prime}$-ATGTCCCACTTGTTCATGATTGCCATGGCATACACCTGGCCCG-3' (reverse); mutagenesis was confirmed by sequencing, and obtained constructs were dubbed pcDNA3.1-DMPK KD. A FLAG epitope was added at the N-terminus of wild-type DMPK by a PCR reaction carried out with a Phusion HF DNA polymerase (New England Biolabs, UK) using the forward 5'-CCGGAATTCTG AAATGTTATGGACTACAAGGATGACGATGACAAATCAGCCGAGGTGCGGCTGA GGCGGC- $3^{\prime}$ and the reverse $5^{\prime}$-ATAGTTTAGCGGCCGCTCAGGGAGC GCGGGCGGCTCCTGGG-3' primers. The amplification product was sub-cloned into pcDNA3.1 $(+)$ and used for transient expression in SAOS-2 wild-type cells. Endogenous DMPK was stably silenced in human RD cells by Mission short hairpin RNA sequences in pLKO.1-PURO vector (Sigma, St. Louis, MO, USA); transfected cells were selected with $1 \mu \mathrm{g} / \mathrm{ml}$ puromycin. Serum and glucose depletion was performed for the indicated times after washing cells twice in PBS by adding DMEM without serum and glucose (Sigma) containing $4 \mathrm{mM}$ L-glutamine, $1 \mathrm{mM}$ sodium pyruvate, $44 \mathrm{mM}$ sodium bicarbonate and $10 \mathrm{mM}$ HEPES. RD cells were differentiated in DMEM supplemented with $2 \% \mathrm{FBS}, 10 \mu \mathrm{g} / \mathrm{ml}$ insulin and $100 \mathrm{nM}$ phorbol 12-myristate 13-acetate. The cell permeable synthetic peptides MIASHLLAYFFTELN- $\beta$ A-GYGRKKRRQRRRG (TAT-HK II) and GYGRKKRRQRRRG- $\beta$ AEEEAKNAAAKLAVEILNKEKK (TAT-Ctr) were prepared by solid-phase peptide synthesis using a multiple peptide synthesizer (Syroll, MultiSynTech GmbH, Witten, Germany), as described previously. ${ }^{40}$

Chemicals and antibodies. FITC-conjugated Annexin- $V$ was from Roche (Basel, Switzerland); Mitosox and tetramethylrhodamine methyl ester (TMRM) were from Molecular Probes (Carlsbad, CA, USA); Srcl-1 was from Tocris Bioscience (Minneapolis, MN, USA); and all other chemicals were from Sigma. The mouse monoclonal anti-HK II, anti-DMPK and anti-SDHA antibodies, and the rabbit polyclonal anti-PARP, anti-MyoD, anti-Tom-20 and goat polyclonal antiCalnexin antibodies were from Santa Cruz Biotechnology (Santa Cruz, CA, USA); the rabbit polyclonal anti-DMPK antibodies were from, ${ }^{5}$ the mouse monoclonal anti-GAPDH and anti-Src antibodies were from Millipore (Billerica, MA, USA); the rabbit polyclonal anti-Caspase-8 antibody was from BD Bioscience (San Jose, CA, USA); the rabbit polyclonal anti-AIF antibody was from Exalpha Biologicals (Shirley, MA, USA); the mouse monoclonal anti-CyP-D and sheep polyclonal antiMn-SOD antibodies were from Calbiochem (Billerica, MA, USA); the mouse monoclonal anti-MHC MF20 antibody was from DSHB (University of lowa, Des Moines, IA, USA); the mouse monoclonal anti-pTyr100 antibody and the rabbit polyclonal anti-pSrcY416, anti-Bcl-X, anti-Omi, anti-cPLA2 and anti-cleaved caspase3 antibodies were from Cell Signaling (Danvers, MA, USA); the mouse monoclonal anti-VDAC1 antibody was a generous gift of Mario Zoratti (University of Padova, Padova, Italy); the mouse monoclonal anti-pSerine and anti-pThreonine were from Qiagen (Venlo, the Netherlands); the mouse monoclonal anti-FLAG was from Agilent and goat polyclonal anti-GST was from GE Healthcare (Waukesha, WI, USA). All other chemicals were form Sigma.

Cell lysis, fractionation and western immunoblot analyses. Total cell extracts were prepared at $4{ }^{\circ} \mathrm{C}$ in $140 \mathrm{mM} \mathrm{NaCl}, 20 \mathrm{mM}$ Tris/HCl $(\mathrm{pH} 7.4)$, $5 \mathrm{mM}$ EDTA, $10 \%$ glycerol and $1 \%$ Triton X-100 in the presence of phosphatase and protease inhibitors (Sigma). All lysates were kept for $30 \mathrm{~min}$ on ice and then cleared by centrifugation at $4{ }^{\circ} \mathrm{C}$ and $14000 \times g$ for $25 \mathrm{~min}$. Protein content was determined with BCA Protein Assay Kit (Thermo Scientific-Pierce, Waltham, MA, USA). To prepare mitochondrial extracts, cells were placed in an isolation buffer (250 mM sucrose, $10 \mathrm{mM}$ Tris/ $\mathrm{HCl}, 10 \mathrm{mM}$ EGTA/Tris, pH 7.4 with phosphatase and protease inhibitors) and homogenized at $4{ }^{\circ} \mathrm{C}$. Mitochondria were then isolated by differential centrifugation (three times, the first at $700 \times g$ and twice at $7000 \times \mathrm{g}$, all at $4{ }^{\circ} \mathrm{C}, 10 \mathrm{~min}$ each) in mitochondrial isolation buffer. Protease digestion of isolated mitochondria was performed in isolation buffer without protease inhibitors for $1 \mathrm{~h}$ at $4^{\circ} \mathrm{C}$. After inactivating trypsin, mitochondria were spun $(18000 \times g$ for $10 \mathrm{~min})$ and lysed. SDS $(0.1 \% \mathrm{w} / \mathrm{v})$ was added to solubilize any residual protease-resistant compartment. Immunoprecipitations were performed with $2 \mathrm{mg}$ of extracted proteins and $4 \mu \mathrm{g}$ of primary antibody per sample. SAOS-2-DMPK or RD-mock total cell lysates were incubated with equal amounts of Sepharose A or Sepharose G (GE Healthcare) as negative controls. Western immunoblots were carried out under standard conditions, and proteins were visualized by enhanced chemiluminescence (Millipore and Euroclone, Milan, Italy). Densitometric analysis was performed with Quantity One software (Bio-Rad Laboratories, Hercules, CA, USA).

GST pull-down experiments. GST pull-down assays were performed on $500 \mu \mathrm{g}$ of pre-cleared total cell lysate of SAOS-2-DMPK cells. Five micrograms of recombinant GST or Src SH3-GST domain (Jena Bioscience, Jena, Germany) were incubated with GST-capture beads (MabTag, Friesoythe, Germany) overnight at $4{ }^{\circ} \mathrm{C}$ in the presence of a proline-rich peptide $(200 \mu \mathrm{M}$, generous gift of Dr. Elena Tibaldi, University of Padova) in lysis buffer supplemented with protease and phosphatase inhibitors.

Phosphorylation assays. In vitro phosphorylation assays were performed on recombinant DMPK and active Src (Millipore) according to the manufacturer's instructions. Briefly, proteins were diluted in $20 \mathrm{mM} \mathrm{MOPS} / \mathrm{NaOH}$ pH $7.0,1 \mathrm{mM}$ EDTA, $5 \%$ glycerol, $0.01 \%$ Brij-35, 0.1\% 2-mercaptoethanol, $1 \mathrm{mg} / \mathrm{ml} \mathrm{BSA}$ to the final concentration and incubated for $20 \mathrm{~min}$ at $30^{\circ} \mathrm{C}$ in $25 \mu$ reactions containing $8 \mathrm{mM}$ MOPS/NaOH pH 7.0, 0,2 mM EDTA, $10 \mathrm{mM} \mathrm{MgAc}, 100 \mu \mathrm{M}$ ATP, protease and phosphatase inhibitors.

Flow cytometry analyses. Flow cytometry recordings were performed as described previously ${ }^{57,58}$ to detect the mitochondrial depolarization (loss of TMRM staining), phosphatidylserine exposure on the cell surface (increased FITCconjugated Annexin- $V$ staining) and loss of plasma membrane integrity (propidium iodide staining, $1 \mu \mathrm{g} / \mathrm{ml}$ ). In addition, mitochondrial superoxide levels were assessed by Mitosox staining, and mitochondrial mass by nonyl acrydil orange (NAO, $20 \mathrm{nM})$ staining, as it binds the mitochondrial membrane lipid cardiolipin. Mitosox $(1 \mu \mathrm{M})$ and TMRM $(20 \mathrm{nM})$ were incubated together with the plasma membrane multidrug resistance pump inhibitor $\mathrm{CsH}(1.6 \mu \mathrm{M}, 30 \mathrm{~min})$, to avoid non-specific cell extrusion of the probes. Samples were analyzed on a FACSCanto II flow cytometer (Becton Dickinson, Franklin Lakes, NJ, USA). Data acquisition and analysis were performed using FACSDiva software (Becton Dickinson).

Immunofluorescence experiments. Cells were washed in PBS, fixed in $4 \%$ paraformaldehyde for $15 \mathrm{~min}$, washed again in PBS and permeabilized in PBS with $0.1 \%$ of Triton and $50 \mathrm{mM} \mathrm{NH}_{4} \mathrm{Cl}$ for $10 \mathrm{~min}$. The primary antibody MHC MF20 was added at $1: 200$ dilution in PBS with $2 \%$ goat serum and incubated overnight at $4{ }^{\circ} \mathrm{C}$ after a sample preincubation in $2 \%$ goat serum at room temperature for $1 \mathrm{~h}$. The secondary antibody (Alexa Fluor 555 Goat Anti-Mouse IgG2b, Molecular Probes) was incubated at 1:400 dilution in PBS with $2 \%$ goat serum for $1 \mathrm{~h}$ at RT. Hoechst $(1 \mu \mathrm{g} / \mathrm{ml})$ was added for $10 \mathrm{~min}$ to stain the nuclei. Images were acquired with a Leica (Wetzlar, Germany) DM IRB inverted fluorescence microscope equipped with a Leica DF300 FX digital camera. Data analysis was performed with Leica IM50 software, and image overlay was carried out with ImageJ software (http://rsb.info.nih.gov/ij/).

Assay of thioredoxin and glutathione reductase activities. After an 8-h incubation in complete or serum- and glucose-free medium, cells were lysed with a modified RIPA buffer $(150 \mathrm{mM} \mathrm{NaCl}, 50 \mathrm{mM}$ Tris-HCl, $1 \mathrm{mM}$ EDTA, $0.1 \%$ SDS, $0.5 \%$ DOC and $1 \%$ Triton X-100) supplemented with $1 \mathrm{mM} \mathrm{NaF}$ and with an antiprotease cocktail (Roche) containing $0.1 \mathrm{mM}$ PMSF. After $40 \mathrm{~min}$ of ice-cold incubation, lysates were centrifuged $(14000 \times g, 5 \mathrm{~min})$, and supernatant aliquots were used for the assessment of enzyme activities. Thioredoxin reductase determination was performed adding $0.25 \mathrm{mM}$ NADPH to samples placed in a $0.2 \mathrm{M} \mathrm{Na}^{+} \mathrm{K}^{+}$phosphate buffer (pH 7.4), with $5 \mathrm{mM}$ EDTA and $1 \mathrm{mM}$ 5,5'-dithiobis(2-nitrobenzoic) acid and monitored as increase of absorbance at $412 \mathrm{~nm}$. Glutathione reductase activity was determined adding $1 \mathrm{mM}$ GSSG to samples placed in $0.1 \mathrm{M}$ Tris/ $/ \mathrm{HCl}$ buffer $(\mathrm{pH} 8.1)$ containing $0.2 \mathrm{mM}$ NADPH; reactions were followed spectrophotometrically at $340 \mathrm{~nm}$ at $25^{\circ} \mathrm{C}$

Glutathione measurements. After an 8-h incubation period in complete or serum- and glucose-free medium, cells were lysed and deproteinized with an aqueous solution of $6 \%$ meta-phosphoric acid. After $10 \mathrm{~min}$ at $4{ }^{\circ} \mathrm{C}$, samples were centrifuged and the supernatants were neutralized with $15 \% \mathrm{Na}_{3} \mathrm{PO}_{4}$ and tested for total glutathione. Sample aliquots were derivatized with 2-vinylpyridine in order to remove the reduced glutathione and determine the oxidized glutathione. Deproteinized samples were washed with $1 \mathrm{ml}$ of ice-cold acetone, centrifuged at $11000 \times \mathrm{g}$, dried and then dissolved in $62.5 \mathrm{mM}$ Tris/HCl buffer $(\mathrm{pH} 8.1)$ containing $1 \%$ SDS and utilized for protein determination.

Intracellular ATP determination. ATP levels were measured on $10^{5}$ cells with the ATP Determination Kit (Molecular Probes) following the manufacturer's instructions. Cells were incubated for $8 \mathrm{~h}$ in complete or serum- and glucosedepleted medium, and the ATP synthase inhibitor oligomycin $(6 \mu \mathrm{M})$ was added for the last $45 \mathrm{~min}$. Cells were lysed in boiling deionized water to denature 
cellular ATPases. ${ }^{59}$ The ATP content was determined with a Fluoroskan Ascent FL instrument (Thermo Fisher Scientific, Waltham, MA, USA) by recording the bioluminescence produced by firefly luciferase and normalized to the amount of protein.

OCR analysis. OCR was measured in situ as reported. ${ }^{60}$ Briefly, monolayers of adherent cells were analyzed with an XF-24 Extracellular Flux Analyzer (Seahorse Bioscience, North Billerica, MA, USA). Cells $\left(3 \times 10^{4}\right.$ per well) were plated the day before the experiment in DMEM. One hour before the experiment, cells were incubated in a DMEM medium without serum supplemented with $4 \mathrm{mM}$ glutamine, $1 \mathrm{mM}$ sodium pyruvate, $10 \mathrm{mM}$ HEPES, with or without $25 \mathrm{mM}$ glucose. Four sequential injections of compounds that affect mitochondrial respiration were performed, in order to measure basal OCR at the beginning of the recordings, the coupled OCR fraction by using the ATP synthase inhibitor oligomycin, the maximal OCR by titrating the respiration uncoupler carbonyl cyanide-4-(trifluoromethoxy) phenylhydrazone (FCCP) and the mitochondria-independent OCR by adding the respiratory chain complex I and complex III inhibitors rotenone and antimycin $A$, respectively. OCR values were then normalized to the sample protein content.

Statistical analysis. All experiments were performed at least three times, and statistical analysis was carried out using a two-tailed Student's $t$-test. Data are presented as mean \pm S.D. Statistical significance was indicated as ${ }^{*} P<0.05$; ${ }^{* *} P<0.01$ and ${ }^{* *} P<0.001$.

\section{Conflict of Interest}

The authors declare no conflict of interest.

Acknowledgements. This work was made possible by grants from Progetti di Ateneo (Grant numbers CPDA101771 and CPDA123598) and Progetto Strategico of the Universita di Padova, from FIRB/MIUR and PRIN/MIUR, and from the Associazione Italiana per la Ricerca sul Cancro (Grant number 8722). We thank Maria Patrizia Schiappelli for skillful technical assistance in peptide purification and Marco Ardina for invaluable assistance with informatics.

1. Cho DH, Tapscott SJ. Myotonic dystrophy: emerging mechanisms for DM1 and DM2. Biochim Biophys Acta 2007; 1772: 195-204.

2. Du H, Cline MS, Osborne RJ, Tuttle DL, Clark TA, Donohue JP et al. Aberrant alternative splicing and extracellular matrix gene expression in mouse models of myotonic dystrophy. Nat Struct Mol Biol 2010; 17: 187-193.

3. Wheeler TM, Thornton CA. Myotonic dystrophy: RNA-mediated muscle disease. Curr Opin Neurol 2007; 20: 572-576.

4. Furling D, Lemieux D, Taneja K, Puymirat J. Decreased levels of myotonic dystrophy protein kinase (DMPK) and delayed differentiation in human myotonic dystrophy myoblasts. Neuromuscul Disord 2001; 11: 728-735.

5. Salvatori S, Fanin M, Trevisan CP, Furlan S, Reddy S, Nagy Jl et al. Decreased expression of DMPK: correlation with CTG repeat expansion and fibre type composition in myotonic dystrophy type 1. Neurol Sci 2005; 26: 235-242.

6. Sarkar PS, Han J, Reddy S. In situ hybridization analysis of Dmpk mRNA in adult mouse tissues. Neuromuscul Disord 2004; 14: 497-506.

7. Berul Cl, Maguire CT, Gehrmann J, Reddy S. Progressive atrioventricular conduction block in a mouse myotonic dystrophy model. $J$ Interv Card Electrophysiol 2000; 4: 351-358.

8. Reddy S, Smith DB, Rich MM, Leferovich JM, Reilly P, Davis BM et al. Mice lacking the myotonic dystrophy protein kinase develop a late onset progressive myopathy. Nat Genet 1996; 13: 325-335.

9. Phillips MF, Harper PS. Cardiac disease in myotonic dystrophy. Cardiovasc Res 1997; 33: 13-22.

10. Kaliman $P$, Llagostera E. Myotonic dystrophy protein kinase (DMPK) and its role in the pathogenesis of myotonic dystrophy 1. Cell Signal 2008; 20: 1935-1941.

11. Forner F, Furlan S, Salvatori $S$. Mass spectrometry analysis of complexes formed by myotonic dystrophy protein kinase (DMPK). Biochim Biophys Acta 2010; 1804: 1334-1341.

12. van Herpen RE, Oude Ophuis RJ, Wijers M, Bennink MB, van de Loo FA, Fransen J et al. Divergent mitochondrial and endoplasmic reticulum association of DMPK splice isoforms depends on unique sequence arrangements in tail anchors. Mol Cell Biol 2005; 25: 1402-1414.

13. Wansink DG, van Herpen RE, Coerwinkel-Driessen MM, Groenen PJ, Hemmings BA, Wieringa B. Alternative splicing controls myotonic dystrophy protein kinase structure, enzymatic activity, and subcellular localization. Mol Cell Biol 2003; 23: 5489-5501.

14. Pall GS, Johnson KJ, Smith GL. Abnormal contractile activity and calcium cycling in cardiac myocytes isolated from DMPK knockout mice. Physiol Genomics 2003; 13: 139-146.
15. Bhagavati S, Leung B, Shafiq SA, Ghatpande A. Myotonic dystrophy: decreased levels of myotonin protein kinase (Mt-PK) leads to apoptosis in muscle cells. Exp Neurol 1997; 146: 277-281.

16. Oude Ophuis RJ, Wijers M, Bennink MB, van de Loo FA, Fransen JA, Wieringa B et al. A tail-anchored myotonic dystrophy protein kinase isoform induces perinuclear clustering of mitochondria, autophagy, and apoptosis. PLoS One 2009; 4: e8024.

17. Loro E, Rinaldi F, Malena A, Masiero E, Novelli G, Angelini C et al. Normal myogenesis and increased apoptosis in myotonic dystrophy type-1 muscle cells. Cell Death Differ 2010; 17: 1315-1324.

18. Yamada H, Nakagawa M, Higuchi I, Horikiri T, Osame M. Detection of DNA fragmentation of myonuclei in myotonic dystrophy by double staining with anti-emerin antibody and by nick end-labeling. J Neurol Sci 2000; 173: 97-102.

19. Usuki F, Takahashi N, Sasagawa N, Ishiura S. Differential signaling pathways following oxidative stress in mutant myotonin protein kinase cDNA-transfected $\mathrm{C} 2 \mathrm{C} 12$ cell lines. Biochem Biophys Res Commun 2000; 267: 739-743.

20. Oshita SE, Chen F, Kwan T, Yehiely F, Cryns VL. The small heat shock protein HspB2 is a novel anti-apoptotic protein that inhibits apical caspase activation in the extrinsic apoptotic pathway. Breast Cancer Res Treat 2010; 124: 307-315.

21. Yoshida K, Aki T, Harada K, Shama KM, Kamoda Y, Suzuki A et al. Translocation of HSP27 and MKBP in ischemic heart. Cell Struct Funct 1999; 24: 181-185.

22. Bigot A, Klein AF, Gasnier E, Jacquemin V, Ravassard P, Butler-Browne $G$ et al. Large CTG repeats trigger p16-dependent premature senescence in myotonic dystrophy type 1 muscle precursor cells. Am J Pathol 2009; 174: 1435-1442.

23. Jackson MJ. Redox regulation of adaptive responses in skeletal muscle to contractile activity. Free Radic Biol Med 2009; 47: 1267-1275.

24. Powers SK, Talbert EE, Adhihetty PJ. Reactive oxygen and nitrogen species as intracellular signals in skeletal muscle. J Physiol 2011; 589: 2129-2138.

25. Pellegrino MA, Desaphy JF, Brocca L, Pierno S, Camerino DC, Bottinelli R. Redox homeostasis, oxidative stress and disuse muscle atrophy. J Physiol 2011; 589: 2147-2160.

26. Rasola A, Bernardi P. Mitochondrial permeability transition in $\mathrm{Ca}(2+)$-dependent apoptosis and necrosis. Cell Calcium 2011; 50: 222-233.

27. Rasola A, Bernardi $P$. The mitochondrial permeability transition pore and its involvement in cell death and in disease pathogenesis. Apoptosis 2007; 12: 815-833.

28. Zorov DB, Juhaszova M, Yaniv Y, Nuss HB, Wang S, Sollott SJ. Regulation and pharmacology of the mitochondrial permeability transition pore. Cardiovasc Res 2009; 83: 213-225.

29. Sun L, Shukair S, Naik TJ, Moazed F, Ardehali H. Glucose phosphorylation and mitochondrial binding are required for the protective effects of hexokinases I and II. Mol Cell Biol 2008; 28: 1007-1017.

30. Wu R, Wyatt E, Chawla K, Tran M, Ghanefar M, Laakso M et al. Hexokinase II knockdown results in exaggerated cardiac hypertrophy via increased ROS production. EMBO MoI Med 2012; 4: 633-646.

31. Miyamoto S, Murphy AN, Brown JH. Akt mediates mitochondrial protection in cardiomyocytes through phosphorylation of mitochondrial hexokinase-ll. Cell Death Differ 2008; 15: 521-529.

32. Robey RB, Hay N. Mitochondrial hexokinases, novel mediators of the antiapoptotic effects of growth factors and Akt. Oncogene 2006; 25: 4683-4696.

33. Ray PD, Huang BW, Tsuji Y. Reactive oxygen species (ROS) homeostasis and redox regulation in cellular signaling. Cell Signal 2012; 24: 981-990.

34. Yoo SK, Starnes TW, Deng Q, Huttenlocher A. Lyn is a redox sensor that mediates leukocyte wound attraction in vivo. Nature 2011; 480: 109-112.

35. Giannoni E, Taddei ML, Chiarugi P. Src redox regulation: again in the front line. Free Radic Biol Med 2010; 49: 516-527.

36. Livigni A, Scorziello A, Agnese S, Adornetto A, Carlucci A, Garbi C et al. Mitochondrial AKAP121 links CAMP and src signaling to oxidative metabolism. Mol Biol Cell 2006; 17: 263-271.

37. Hebert-Chatelain $\mathrm{E}$. Src kinases are important regulators of mitochondrial functions. Int J Biochem Cell Biol 2013; 45: 90-98.

38. Murphy MP. How mitochondria produce reactive oxygen species. Biochem J 2009; 417: 1-13.

39. Mailloux RJ, Dumouchel T, Aguer C, deKemp R, Beanlands R, Harper ME. Hexokinase II acts through UCP3 to suppress mitochondrial reactive oxygen species production and maintain aerobic respiration. Biochem $J$ 2011; 437: 301-311.

40. Chiara F, Castellaro D, Marin O, Petronilli V, Brusilow WS, Juhaszova M et al. Hexokinase II detachment from mitochondria triggers apoptosis through the permeability transition pore independent of voltage-dependent anion channels. PLoS One 2008; 3: e1852.

41. Roskoski R Jr. Src kinase regulation by phosphorylation and dephosphorylation. Biochem Biophys Res Commun 2005; 331: 1-14.

42. Bouche M, Canipari R, Melchionna R, Willems D, Senni MI, Molinaro M. TGF-beta autocrine loop regulates cell growth and myogenic differentiation in human rhabdomyosarcoma cells. Faseb J 2000; 14: 1147-1158.

43. Sellers JR. Myosins: a diverse superfamily. Biochim Biophys Acta 2000; 1496: 3-22.

44. Yeatman TJ. A renaissance for SRC. Nat Rev Cancer 2004; 4: 470-480.

45. Cesaro L, Salvi M. Mitochondrial tyrosine phosphoproteome: new insights from an up-todate analysis. Biofactors 2010; 36: 437-450.

46. Azzolin L, Antolini N, Calderan A, Ruzza P, Sciacovelli M, Marin O et al. Antamanide, a derivative of Amanita phalloides, is a novel inhibitor of the mitochondrial permeability transition pore. PLoS One 2011; 6: e16280. 
47. Machida K, Ohta Y, Osada H. Suppression of apoptosis by cyclophilin D via stabilization of hexokinase II mitochondrial binding in cancer cells. J Biol Chem 2006; 281: 14314-14320.

48. Masgras I, Rasola A, Bernardi P. Induction of the permeability transition pore in cells depleted of mitochondrial DNA. Biochim Biophys Acta 2012; 1817: 1860-1866.

49. Chiara F, Gambalunga A, Sciacovelli M, Nicolli A, Ronconi L, Fregona D et al. Chemotherapeutic induction of mitochondrial oxidative stress activates GSK- $3 \alpha / \beta$ and Bax, leading to permeability transition pore opening and tumor cell death. Cell Death Dis 2012; 3: e444.

50. Llagostera E, Catalucci D, Marti L, Liesa M, Camps M, Ciaraldi TP et al. Role of myotonic dystrophy protein kinase (DMPK) in glucose homeostasis and muscle insulin action. PLoS One 2007; 2: e1134.

51. Savkur RS, Philips AV, Cooper TA. Aberrant regulation of insulin receptor alternative splicing is associated with insulin resistance in myotonic dystrophy. Nat Genet 2001; 29: 40-47.

52. Bonnard C, Durand A, Peyrol S, Chanseaume E, Chauvin MA, Morio B et al. Mitochondria dysfunction results from oxidative stress in the skeletal muscle of diet-induced insulinresistant mice. J Clin Invest 2008; 118: 789-800.

53. Houstis N, Rosen ED, Lander ES. Reactive oxygen species have a causal role in multiple forms of insulin resistance. Nature 2006; 440: 944-948.

54. Tominaga K, Hayashi YK, Goto K, Minami N, Noguchi S, Nonaka I et al. Congenital myotonic dystrophy can show congenital fiber type disproportion pathology. Acta Neuropathol 2010; 119: 481-486.

55. Vihola A, Bassez G, Meola G, Zhang S, Haapasalo H, Paetau A et al. Histopathological differences of myotonic dystrophy type 1 (DM1) and PROMM/DM2. Neurology 2003; 60 1854-1857.
56. Yan Z, Okutsu M, Akhtar YN, Lira VA. Regulation of exercise-induced fiber type transformation, mitochondrial biogenesis, and angiogenesis in skeletal muscle. J Appl Physiol 2011; 110: 264-274

57. Gramaglia D, Gentile A, Battaglia M, Ranzato L, Petronilli V, Fassetta M et al. Apoptosis to necrosis switching downstream of apoptosome formation requires inhibition of both glycolysis and oxidative phosphorylation in a BCL-X(L)- and PKB/AKT-independent fashion. Cell Death Differ 2004; 11: 342-353.

58. Rasola A, Geuna M. A flow cytometry assay simultaneously detects independent apoptotic parameters. Cytometry 2001; 45: 151-157.

59. Yang NC, Ho WM, Chen YH, Hu ML. A convenient one-step extraction of cellular ATP using boiling water for the luciferin-luciferase assay of ATP. Anal Biochem 2002; 306 : 323-327.

60. Sciacovelli M, Guzzo G, Morello V, Frezza C, Zheng L, Nannini N et al. The mitochondrial chaperone TRAP1 promotes neoplastic growth by inhibiting succinate dehydrogenase. Cell Metab 2013: 17: 988-999.

Cell Death and Disease is an open-access journal published by Nature Publishing Group. This work is licensed under a Creative Commons Attribution-NonCommercialShareAlike 3.0 Unported License. To view a copy of this license, visit http://creativecommons.org/licenses/by-nc-sa/3.0/

Supplementary Information accompanies this paper on Cell Death and Disease website (http://www.nature.com/cddis) 